Acta Poetica 29-1

PRIMAVERA

2008

\title{
El discurso ajeno en los titulares periodísticos
}

\author{
Juan Nadal Palazón
}

En este trabajo se propone, a partir de un corpus de titulares periodísticos, un modelo de clasificación del discurso ajeno basado en tres variedades puras - estilo directo, estilo indirecto y voz narrada - y en varias combinaciones entre éstas. Por medio de un análisis cuantitativo, se revelan tendencias generales y comportamientos específicos de los diarios en lo concerniente a los mecanismos generales que suponen alusión o presencia de una enunciación ajena en la propia. Se evidencian, asimismo, los sesgos que comportan las clasificaciones tradicionales.

In this paper, it is proposed, starting from a journalistic headline's corpus, a classification model for the "alien discourse", based on three pure varieties - direct speech, indirect speech, and narrativized speech-, and on several combinations of these. By means of a quantitative analysis, there are revealed general tendencies and specific behaviors of the journals, considered in relation to general mechanisms which suppose allusion to or presence of an alien enunciation within one's own. The slopes which bear the traditional classifications are evidenced as well.

Palabras clave: periódico, titulares, discurso ajeno, estilo directo, estilo indirecto, voz narrada 

Acta Poetica 29-1

PRIMAVERA

2008

Juan Nadal Palazón

\section{El discurso ajeno en los titulares periodísticos}

\section{Introducción}

El procesamiento del habla ajena en el discurso propio es un asunto fundamental de la lingüística. Tan es así que, desde hace ya algunos años, se ha venido planteando la posibilidad de que se trate de la esencia misma de la lengua. ${ }^{1}$ Se ha dicho también que el generar imágenes de otros discursos es una capacidad del discurso mismo en todas las lenguas del mundo, ${ }^{2}$ e incluso que constituye un rasgo general del comportamiento humano. ${ }^{3}$

Esta investigación busca caracterizar y describir tales mecanismos a partir de un corpus de 2396 titulares publicados durante el año 2005 en los diarios mexicanos La Prensa, Reforma, La Jornada, El Universal y El Sol de México. ${ }^{4}$ Los encabezados son, para Van Dijk, "la parte más importante del

${ }^{1}$ Bajtín (1935) 1986 y (1963) 1986; Voloshinov (1929) 1992.

2 Jakobson (1936-1963) 1981, 308-309; Li 1986, 39-40; Collins 2001, 1; Sakita 2002, 2; Coulmas 1986, 2, entre otros.

${ }^{3}$ Haberland 1986, 219.

${ }^{4}$ Los diarios considerados integran el corpus en las proporciones siguientes: La Prensa, 15.1\% (362/2396); Reforma, 17.1\% (410/2396); La Jornada, 17.7\% (425/2396); El Universal, 19.3\% (462/2396), y El Sol de México, 30.8\% (737/2396). 
texto" $"$ periodístico, y, para Steel, "la forma periodística por antonomasia". ${ }^{6}$ Son textos producidos en situaciones enunciativas que llevan al límite la tensión entre economía e informatividad, y constituyen las únicas secuencias leídas por gran parte de los consumidores de diarios. ${ }^{7}$ Esto, aunado al hecho de que más del $60 \%$ de las noticias se origina en declaraciones, ${ }^{8}$ hace de éste un registro lingüístico ideal para estudiar dichos procedimientos. Además, como veremos, el uso discursivo de los titulares ha desarrollado estructuras lingüísticas propias, difícilmente empleadas en otras situaciones de habla.

Es preciso aclarar que, aunque muy abundante, la bibliografía alusiva al discurso ajeno se antoja insuficiente y, en algunos casos, francamente caduca. Sólo en fechas recientes el discurso ajeno ha recibido la atención de lingüistas, y ya no únicamente de teóricos o críticos de la literatura. Si bien las aportaciones de la teoría literaria han sido fecundas, es obvio que el asunto trasciende los límites de tal uso discursivo. La mayoría de los trabajos con orientación lingüística, sin embargo, suele reducir el problema a fenómenos sintácticos de alcance estrictamente oracional, como ocurre en casi todas las gramáticas españolas que no ignoran el asunto. El carácter heterogéneo, dinámico y complejo del discurso ajeno plantea ciertas dificultades no resueltas en la bibliografía especializada que será necesario atender para lograr una adecuada clasificación del material recogido.

En definitiva, como afirman Janssen y Van der Wurff, ${ }^{9}$ ni siquiera existe consenso en la terminología empleada en los estudios especializados: se impone, pues, la necesidad de definir, brevemente, los términos que aquí serán empleados. Entiendo

\footnotetext{
${ }^{5}$ Van Dijk (1988) 1997, 134.

${ }^{6}$ Steel 1971, 15 .

${ }^{7}$ Emig 1927; Eco 1977; Casado Velarde 1984.

${ }^{8}$ Nadal 2009, 22.

${ }^{9}$ Janssen y Van der Wurff 1996, 3.
} 
por discurso ajeno no sólo las palabras generadas por otro locutor, sino también, por extensión, todo discurso o segmento discursivo que trasluzca, de manera explícita o implícita, la alusión o presencia de una enunciación ajena en la propia. ${ }^{10}$ Siguiendo a Voloshinov, ${ }^{11}$ llamaré primaria a la enunciación propia, y secundaria, a la ajena; en el discurso ajeno, la enunciación primaria trasluce siempre una enunciación secundaria. Para abreviar, llamaré L1 al locutor de la enunciación primaria, y L2, al de la secundaria. ${ }^{12}$

De acuerdo con este mismo autor, discurso ajeno no sólo es "discurso en el discurso, enunciado dentro de otro enunciado", sino también "discurso sobre otro discurso, enunciado acerca de otro enunciado". ${ }^{13}$ La noción de discurso ajeno abarca, pues, los términos de discurso referido y de discurso reproducido, que se oponen por la condición de representatividad: ${ }^{14}$ para hablar de discurso reproducido es necesario que, entre la cadena verbal resultante de la enunciación primaria y el producto lingüístico de la enunciación secundaria, exista una cierta relación de semejanza. ${ }^{15} \mathrm{El}$ discurso referido, en cambio, no implica representatividad: "tan sólo describe una acción realizada verbalmente", ${ }^{16}$ sin necesidad de evocar icónicamente el

${ }^{10} \mathrm{Si}$ bien es cierto que, en sentido estricto, el discurso ajeno es aquel que genera cualquier sujeto de una enunciación ajena, en este trabajo he reservado el término para referirme a los mecanismos lingúísticos por los que, en un enunciado, se alude o representa la enunciación o el enunciado que supuestamente ha producido otra persona.

${ }^{11}$ Voloshinov (1929) 1992.

${ }^{12}$ Me baso en la nomenclatura propuesta por Ducrot ([1984] 1986, 198): "Entiendo por locutor a un ser que, en el sentido mismo del enunciado, es presentado como su responsable, es decir, como alguien a quien se debe imputar la responsabilidad de ese enunciado. A él remiten el pronombre yo y las otras marcas de primera persona". En mis materiales, el locutor primario coincide siempre con la entidad que este lingüista denomina productor empírico, es decir, el ser de la realidad factual que produce el enunciado: en todos los casos de mi corpus se trata del periodista redactor del titular.

${ }^{13}$ Voloshinov (1929) 1992, 155. Cursivas en el original.

${ }^{14}$ Maldonado 1991, 20.

${ }^{15}$ Reyes 1984, 1993 y 1994; Maldonado 1991 y 1999.

${ }^{16}$ Maldonado 1991, 20, y 1999, 3556. 
enunciado original. ${ }^{17}$ Como bien apunta Maldonado, "reproducir supone siempre referir, pero no al contrario". ${ }^{18}$

La noción de discurso ajeno abarca todos los discursos o segmentos discursivos que traslucen alusión o presencia de una enunciación ajena en la propia. Los indicios de dicho traslucimiento pueden hallarse ya en el nivel textual, ya en el contextual, ya en el suprasegmental; el discurso ajeno es, en gran parte, un asunto de índole discursiva, no solamente oracional. ${ }^{19}$ Dado que se trata de alusión o presencia, quedan comprendidos, pues, los términos discurso referido y discurso reproducido.

En este trabajo propongo, con base en lo anterior, un modelo de clasificación del discurso ajeno basado en tres variedades puras y en varias combinaciones entre éstas. Aunque erigido sobre una descripción de titulares periodísticos, el esquema modélico general puede hacerse extensivo a otros usos discursivos de la lengua española. El análisis se sustenta de manera especial en métodos cuantitativos, con la finalidad de determinar la importancia relativa de las distintas modalidades discursivas, así como de identificar tendencias generales del discurso de los titulares y comportamientos específicos de los diarios considerados.

\section{Estilo directo}

El estilo directo se caracteriza por la retención del sistema deíctico de L2 en el segmento que representa la declaración

${ }^{17}$ Parmentier 1993; Waugh 1995.

${ }^{18}$ Maldonado 1991, 20.

${ }^{19}$ Reyes 1993, 9; Collins 2001, 97, y Sakita 2002, 9, entre otros. Muchos especialistas, sin embargo, han restringido sus estudios sobre discurso ajeno a descripciones de estructuras sintácticas; casi todas las gramáticas españolas que no ignoran el tema se hallan en este caso (Jespersen [1924] 1968; RAE [1931] 1962 y 1973; Gili Gaya 1967; Banfield 1973; Partee 1973; Wierzbicka 1974; Alcina y Blecua [1975] 2001; Comrie 1986; Li 1986; Hand 1991). 
ajena, y se asocia convencionalmente con el polo semántico de una supuesta retransmisión literal; comporta una actitud histriónica por parte de L1, y, en consecuencia, una intención mimética. ${ }^{20}$ En función de su complejidad estructural, ${ }^{21}$ se identifican dos grandes variedades: marcado y no marcado.

Una marca de estilo directo es cualquier forma que se añada al presunto enunciado de L2 para sugerir la existencia de una retransmisión literal. Puede ser morfológica, sintáctica, ortográfica o suprasegmental, siempre que se trate de un exponente formal, explícito, añadido al enunciado de L2: la adición formal al supuesto enunciado originario conlleva, desde luego, un aumento de complejidad estructural. ${ }^{22}$ Quedan excluidas, por ende, todas las marcas implícitas, frecuentemente aludidas por la teoría literaria, como la distintiva manera de hablar de un personaje.

La tradición gramatical ha centrado buena parte de su atención en las características de lo que aquí llamo estilos marcados (directo e indirecto): no son pocos los estudiosos que sólo toman en cuenta estas variedades para caracterizar el discurso ajeno. ${ }^{23}$ Desde que se popularizó el término estilo indirecto libre, acuñado por Bally, ${ }^{24}$ diversos autores han añadido un tercer estilo que combina propiedades, casi siempre sintácticas, de las dos variedades hasta entonces descritas. ${ }^{25}$ Debido a las

${ }^{20}$ Wierzbicka 1974, 272; Maingueneau 1981, 99; Li 1986, 34; Coulmas 1994, 3552; Reyes 1993, 15, y 1994, 612; Nadal 2009, 18-22, entre otros.

${ }^{21}$ Givón 1995, 28.

${ }^{22}$ Algunos autores reducen la noción de estilo directo marcado al tipo de discurso ajeno "introducido por algún signo gráfico en el texto: guiones, comillas, cursiva" (Sánchez-Rey 1991, 131). Claro está que, si concebimos marca como elemento adicionador de complejidad estructural, asociado en este caso con una supuesta retransmisión literal, el problema no puede resolverse apelando únicamente a cuestiones ortográficas.

23 RAE (1931) 1962, § 382; Gili Gaya 1967, \$ 219.1I; Partee 1973; Comrie 1986; Li 1986; Hand 1991, entre muchos otros.

${ }^{24}$ Bally 1912.

25 Jespersen (1924) 1968, 349; Genette (1972) 1989, 231; Banfield 1973, 10-13; RAE 1973, \$ 3.19.4b; Wierzbicka 1974, 294-297; Alcina y Blecua (1975) 2001, 
ambiguas definiciones y a la falta de consenso en las propuestas de clasificación, el "estilo indirecto libre" se ha convertido en una categoría donde, de manera muchas veces confusa y desordenada, suelen agruparse todas las formas de reproducción discursiva que no se ajustan estrictamente a los patrones estereotipados de los estilos marcados: ${ }^{26}$ "la forma situada entre el estilo directo y el indirecto se llama estilo indirecto libre", ${ }^{27}$ dicen Leech y Short, por ejemplo.

En este trabajo, no recurriré a esta arraigada categorización tripartita - estilos directo, indirecto e indirecto libre- por cuanto resulta muy limitada para caracterizar los titulares periodísticos: en primer lugar, excluye las variedades del discurso ajeno que no implican reproducción discursiva, y, en segundo, confunde en una misma categoría variedades que presentan características formales y funcionales diversas. ${ }^{28}$ Como veremos más adelante, la mayoría de los titulares periodísticos con discurso ajeno se ubica en alguna de estas dos áreas.

(1) a. Ojalá te pudras, le gritan a asesino de una joven en Juárez [sol 22/02/05: 1/B] ${ }^{29}$

$\$$ 8.4.1.1, entre otros. Según Coulmas (1986, 6-10), ya hablaban de "formas mezcladas" Tobler, en 1894, y Kalepky, en 1899 (cf. Voloshinov [1929] 1992, 187191).

${ }^{26}$ Con relativa frecuencia, el "estilo indirecto libre" se asocia con las diversas técnicas que el lenguaje literario, o con intención literaria, emplea para representar situaciones cercanas al monólogo interior. Reyes $(1994,610)$, por ejemplo, afirma que se trata exclusivamente de un "fenómeno del lenguaje literario", consistente en una "traslación de discurso sui generis, que presenta los contenidos de la conciencia de un personaje". Al margen de que ésta no es una idea que goce de total aceptación entre los especialistas, parece evidenciar, una vez más, que es necesario sustentar las generalizaciones gramaticales en materiales que reúnan diversos usos discursivos.

27 "The form in between DS [direct speech] and IS [indirect speech] is called free indirect speech (FIS)" (Leech y Short 1981, 325).

${ }^{28}$ Cf. Nadal 2009.

${ }^{29}$ En todos los encabezados reproducidos en este trabajo, he respetado fielmente la ortografía literal y puntual de los originales. He conservado también los usos de mayúsculas y minúsculas. Asimismo, he transcrito los encabezados en letras de espesor regular, bien entendido que los titulares siempre se imprimen en negrillas. Entre corchetes añado la referencia del texto: coloco primero el nombre del perió- 
b. Planean mi asesinato en Washington: H. Chávez [LAP 21/02/05: 4]

c. "¿Qué habéis hecho conmigo?" [LAP 26/02/05: 9]

d. "Somos hijos de la volcana", dicen al recordar la erupción del Paricutín [JOR 22/02/05: 12a]

e. Fox no logrará callarme, dice López Obrador [JOR 23/02/05: 1]

f. ¡NO ME CALLARÁ! [LAP 23/02/05: 1]

Los titulares presentan dos tipos de marcas de estilo directo: verbo de habla subordinante e índices gráficos. En los titulares (1a) y (1e), el primitivo enunciado de L2 está subordinado, en función de objeto directo, a una oración principal, atribuida a L1, que contiene un verbo de habla expreso. En (1b), el verbo de habla se encuentra elidido, y en su lugar se emplean los dos puntos: como se sabe, este fenómeno, que Alarcos ${ }^{30}$ denomina "bimembración expresiva", produce configuraciones de representación discursiva propias de los titulares periodísticos. La supuesta retransmisión literal está indicada en (1c) por medio de las comillas, es decir, ortográficamente. El estilo directo está doblemente marcado en (1d), pues presenta verbo de habla y comillas. Por último, el titular (1f) alude al mismo acto de habla que (1e), pero el encabezado no puede interpretarse como discurso ajeno sin atender al contexto: constituye un ejemplo de estilo directo no marcado.

Del total de mis materiales, el 23\% (550/2396) corresponde al estilo directo. ${ }^{31}$ Las frecuencias relativas, para el total de titulares con discurso ajeno de cada periódico, son las siguientes: Reforma, 6.3\% (26/410); El Universal, 20.3\% (94/462);

\footnotetext{
dico, abreviado y en versalitas; después de un espacio, la fecha, y, por último, tras dos puntos, la página. Al final de este trabajo se encuentra la correspondiente lista de abreviaturas.

${ }^{30}$ Alarcos 1977, 146.

${ }^{31}$ Por diarios, la distribución global del estilo directo es la siguiente: Reforma, 5\% (26/550); El Universal, 17\% (94/550); La Prensa, 25\% (135/550); La Jornada, 25\% (140/550); El Sol de México, 28\% (155/550).
} 
Gráfica 1

Proporción de estilo directo en cada periódico

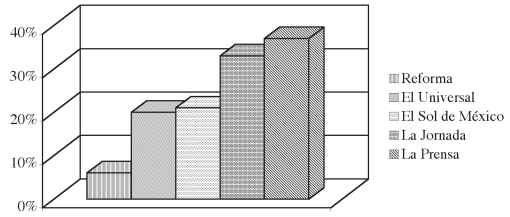

El Sol de México, 21\% (155/737); La Jornada, 32.9\% (140/425), y La Prensa, 37.3\% (135/362). El 98\% de los titulares en estilo directo (539/550) está representado por formas marcadas, y sólo el $2 \%(11 / 550)$ por no marcadas.

Puede advertirse que, en el caso de Reforma, existe una clara tendencia a evitar el uso del estilo directo; en La Jornada y La Prensa, en cambio, se redacta en estilo directo aproximadamente la tercera parte de todos los titulares con discurso ajeno. El Universal y El Sol de México están en una posición intermedia.

\section{Estilo indirecto}

El estilo indirecto siempre presenta una reformulación analítica del enunciado secundario, la cual comporta transposiciones deícticas de persona cuando en el enunciado primario se alude explícitamente a algún participante de los cuadros figurativos de la enunciación primaria o secundaria. Esta representación de las palabras ajenas puede ser más o menos icónica ${ }^{32}$ - esto es, más o menos parecida al enunciado original - , dependiendo

${ }^{32}$ Waugh 1995, 155. 
de si se trata de una reformulación analítico-discursiva o analítico-temática, ${ }^{33}$ es decir, de si se respetan las palabras y los giros característicos del habla de L2, o si se resumen o parafrasean las palabras ajenas. En cualquier caso, el contexto producido es transparente, ${ }^{34}$ pues no hay más que un eje deíctico - el de $\mathrm{L} 1-$, condición esta que lo hace carecer de histrionismo. ${ }^{35}$

$\mathrm{Al}$ igual que el estilo directo, el indirecto presenta, según mi corpus, dos grandes variedades: una, caracterizada por la presencia explícita de algún elemento lingüístico que sugiera la existencia de una retransmisión analítica, que llamo estilo indirecto marcado, y otra, identificable por la ausencia de toda indicación formal en el titular, que denomino estilo indirecto no marcado. De acuerdo con la ScaPoLine, en el primero hay siempre una "polifonía abierta", y en el segundo, una "disimulada". ${ }^{36}$

Entiendo por marca de estilo indirecto cualquier forma que se añada explícitamente a la expresión transpuesta del enunciado primitivo a fin de sugerir la existencia de una reformulación analítica. En mis materiales registro, como marca prototípica, la concurrencia de un verbo de habla y de una conjunción subordinante, y, como marcas no prototípicas, la sola presencia explícita del verbo o de la conjunción, además del morfema desinencial -ría usado con valor de potencial citativo. En otras palabras, la construcción prototípica del estilo indirecto consta tanto de un verbo subordinante cuanto de una conjunción indicadora de la hipotaxis, mientras que las construcciones no prototípicas se caracterizan por la elisión de cualquiera de los elementos constitutivos de dicho binomio, o bien por el uso del morfema -ría. ${ }^{37}$

${ }^{33}$ Voloshinov (1929) 1992, 173-174.

${ }^{34}$ Maldonado 1991, 73.

${ }^{35}$ Wierzbicka 1974, 284.

${ }^{36}$ Nølke, Fløttum y Norén 2004, 64.

${ }^{37}$ Claro está que, en los casos de pospretérito y antepospretérito, la adición del morfema -ría supone la sustitución del morfema de tiempo correspondiente a la forma transpuesta del supuesto enunciado original. 
(2) a. Advierte el Unicef que uno de cada 12 niños son explotados en el mundo [SOL 22/02/05: 15/A]

b. Dice Salinas Pliego asistirá a corte de EU [REF 25/02/05: NEG 18]

c. Que E. Salinas no fue asesinado en Huixquilucan [LAP 22/02/05: 10]

d. Habría utilizado la CIA un Boeing 737 para transportar a presuntos terroristas [SOL 21/02/05: 15/A]

e. En el mundo explotan a uno de cada 12 niños [UNI 22/02/05: A7].

Ejemplifico con (2a) los casos de estilo indirecto marcado con verbo y conjunción expresos. En (2b) se elide la conjunción y, en (2c), el verbo de habla. El encabezado (2d) constituye un testimonio de uso de antepospretérito con valor de potencial citativo, es decir, en palabras de Lapesa, un "signo de discurso indirecto no atribuido concretamente a nadie", que se emplea, sobre todo en el discurso periodístico, para "dar a entender que se trata de aseveraciones ajenas, suposiciones cuya veracidad no se asegura o rumores no confirmados", donde "el hablante nada afirma por su cuenta, como si se escuchara un 'dicen que', 'se rumorea que' implícitos". ${ }^{38}$ El titular (2e) alude a la misma declaración que (2a), pero sin indicaciones explícitas: es, por tanto, un caso de estilo indirecto no marcado.

En mis materiales, el estilo indirecto constituye la variedad de discurso ajeno más abundante: representa el 46\% (1103/2396) del corpus. ${ }^{39}$ Este dato permite asegurar que existe una tendencia de la prensa mexicana a formular en estilo indirecto los titulares con discurso ajeno, ${ }^{40}$ la cual está particularmente acentuada en algunos diarios: Reforma, El Universal

${ }^{38}$ Lapesa 1977, 227.

${ }^{39}$ Proporciones globales por periódico: Reforma, 18\% (199/1103); El Universal, 20.5\% (226/1103); La Prensa, 12.5\% (138/1103); La Jornada, 15.2\% (168/1103); El Sol de México 33.7\% (372/1103).

${ }^{40}$ Fairclough $(1988,127)$ y Bell $(1991,209)$ llegaron a conclusiones similares para los artículos publicados en diarios anglosajones. 


\section{Gráfica 2}

Proporción de estilo indirecto en cada periódico

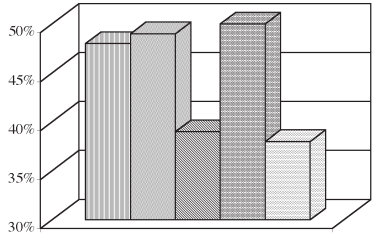

III Reforma

El Universal

ㄸ. La Jornada

- El Sol de México

ㄴ. La Prensa

y El Sol de México presentan en estilo indirecto aproximadamente la mitad de todos sus titulares con discurso ajeno, mientras que en La Jornada y La Prensa las frecuencias relativas de uso no alcanzan el $40 \%$. Éstas son las proporciones exactas: La Prensa, 38.1\% (138/362); La Jornada, 39.5\% (168/425); Reforma, 48.5\% (199/410); El Universal, 48.9\% (226/462); El Sol de México, $50.5 \%$ (372/737).

El $90.6 \%$ (999/1103) de los titulares en estilo indirecto de los cinco diarios está representado por el estilo indirecto no marcado, mientras que sólo el 9.4\% (104/1103) corresponde a formas marcadas.

\section{Voz narrada}

Las formas narrativizadas del discurso ajeno presentan el acto de habla original como cualquier otro tipo de acción ${ }^{41}$ y "permiten resumir brevemente la acción comunicativa sin informar

41 "The speech act is reported in a way that puts it on a par of other kinds of action" (Leech y Short 1981, 324). 
sobre el contenido proposicional del discurso citado". ${ }^{42}$ Muy diversos son los autores que, además de reconocer la existencia de este tipo de secuencias, sugieren que se trata de formas del discurso ajeno. ${ }^{43}$ La mayoría de ellos, sin embargo, no les dedica más de unas cuantas líneas.

Como es natural en la designación de un concepto nuevo, los apelativos propuestos son muy variados: "discurso narrativizado", 44 "reporte narrativo del acto verbal", 45 "voz referida", 46 "discurso sumergido", 47 "resumen de la historia", ${ }^{48}$ "sumario diegético" ${ }^{49}$ y otros más. ${ }^{50}$ En este trabajo he adoptado el término voz narrada por tratarse del único que, hasta donde tengo conocimiento, ha surgido en el ámbito de la lingüística hispánica. $^{51}$

(3) a. Sergio Andrade se dice inocente en audiencia [UNI 22/02/05: E1]

b. HABLAN A NIÑOS DEL DESAFUERO [UNI 24/02/05: C4]

c. Se burla de adversarios [UNI 24/02/05: A10]

d. Asegura Marina tener un bajo número de quejas [UNI 22/02/05: A15]

e. Condolencias del Ejecutivo por la muerte del gobernador [LAP 26/02/05: 35]

${ }^{42}$ Fonte 1998,34

${ }^{43}$ Genette (1972) 1989, 228 y (1993) 1998, 40; Page 1973, 35-37; Bal (1978) 1990, 141; McHale, 1978, 258; Leech y Short 1981, 323; Toolan 1988, 122; Wales, 1989, 314-315; Chafe 1994; Perret 1994, 101; Fonte 1996, 41-48; 1998, 34; Collins 2001, 124-125; Sakita 2002, 190.

44 "Discours narrativisé" (Genette [1972] 1989, 228; Perret 1994, 101).

45 "Narrative report of speech act" (Leech y Short 1981, 323-324; Wales 1989, 314-315).

${ }^{46}$ Beltrán Almería 1992, 87-93.

47 "Submerged speech" (Page 1973, 35-37).

${ }^{48} \mathrm{Bal}(1978) 1990,141$.

49 "Diegetic summary" (McHale 1978, 258).

50 "Narrational summary speech" (Toolan 1988, 122), "refered-to speech" (Chafe 1994).

${ }^{51}$ Fonte 1998, 34, y 2002, 31. 
En cada uno de estos ejemplos, el locutor primario alude expresamente a un acto de habla ajeno, pero sin recurrir a las estructuras de los estilos directo o indirecto marcados: el hecho de habla es "tratado como un acontecimiento [...] y asumido como tal por el propio narrador". ${ }^{52}$ Esto quiere decir que L1 refiere el acto de habla de L2 por medio de estructuras textuales usadas habitualmente para narrar acciones no verbales, es decir, para componer lo que Genette denomina relato de acontecimientos: la voz narrada ocupa el linde entre relato de palabras y relato de acontecimientos.

Puede advertirse que los titulares de la serie (3) presentan distintos grados de especificación del contenido expresado originalmente por L2: en (3a) se representan, aunque de manera muy escueta, las palabras de L2; en (3b) no se especifica más que el tema general del discurso referido, y en (3c) sólo se refiere y describe una acción realizada verbalmente..$^{53}$ Como bien sugiere McHale, ${ }^{54}$ la voz narrada tiene la facultad de ser más o menos diegética, dependiendo de si se especifica el contenido del enunciado original o no. ${ }^{55}$

El hecho de que existan formas de voz narrada con cierto grado de representación discursiva constituye una evidencia que refuta acaso definitivamente el argumento esgrimido por no pocos especialistas para justificar la tenaz exclusión de que esta categoría ha sido objeto en casi todos los estudios gramaticales del discurso ajeno: quienes no ignoran del todo el asunto suelen argüir que, en las formas narrativizadas, "no puede percibirse citación alguna", ${ }^{56}$ puesto que, dicen, ésta se deli-

${ }_{52}$ Genette (1972) 1989, 227.

${ }^{53}$ Así lo revela el contexto linguiístico: “Andrés Manuel López Obrador, jefe de gobierno del Distrito Federal, no quiso responder a las críticas de Santiago Creel [...] con el argumento de que 'me da flojera'. [...] Además, continuó con los señalamientos contra sus adversarios, de quienes opinó: 'Por poco les sale una hernia en el cerebro de tanto pensar' cuando defienden el estado de derecho y aseguran que 'la ley es la ley, brillante ¿no?"” (UNI 24/02/05: A10).

${ }_{54}^{54}$ McHale 1978.

${ }_{55}^{55}$ Cf. Leech y Short 1981, 323-324.

${ }^{56}$ Reyes $1984,78$. 
mita por la "condición" de representatividad discursiva, definitoria para ellos del discurso ajeno. ${ }^{57}$

El origen de la confusión parece radicar en que los estudios del discurso ajeno no suelen estar sustentados en corpus estrictamente recopilados: los analistas, confiados la mayoría de las veces en su intuición lingüística, no tienen en mente casos como (3a), o los omiten de manera deliberada. Autores hay, es verdad, que, a pesar de adherirse a la hipótesis de la representatividad como condición sine qua non del discurso ajeno, advierten el grave sesgo que ésta supone. ${ }^{58}$ En cualquier caso, me parece que deben replantearse los criterios definitorios del discurso ajeno, como se ha hecho aquí, siguiendo la pauta trazada por Voloshinov hace ya algunos años.

La representación discursiva tampoco es, desde luego, el rasgo definitorio de la voz narrada: como he dicho - y ejemplificado con (3c) - , esta variedad del discurso ajeno es la única que puede referir una enunciación ajena sin representar su contenido. Para caracterizarla, acudo aquí también al principio de la correspondencia irrenunciable entre forma y significado en configuraciones gramaticales abstractas: ${ }^{59}$ la voz narrada presenta características formales y funcionales que, al menos en los titulares periodísticos, la distinguen claramente de las demás variedades del discurso ajeno.

A diferencia de los estilos directo e indirecto marcados, la voz narrada no sólo admite verbos de habla transitivos y prepositivos, sino también intransitivos. Al igual que el estilo directo, y a diferencia del indirecto, admite objetos directos no oracionales; a diferencia de éste, y al igual que el indirecto, sus objetos directos nunca se enlazan con el núcleo del predicado por medio de signos gráficos. Aunque en muy baja pro-

${ }^{57}$ Cf. Maldonado 1991, 20, y Reyes 1993, 12, por ejemplo.

58 "I am unable to suggest any coherent solution, as all the possible analyses that I can see seem to involve grave difficulties" (Wierzbicka 1974,294).

${ }^{59}$ Fillmore 1982, Goldberg 1995, y Kay 1997, entre otros. 
porción, también se estructura en frases que tienen por núcleo la nominalización de un verbo de habla.

Dicho de otro modo, la voz narrada se estructura en frases nominales (ejemplo [3e]) o bien en predicados intransitivos o transitivos ([3a] a [3d]), y, en el caso de estos últimos, los objetos directos o prepositivos, oracionales o no, jamás están separados del resto del titular por medio de índices gráficos. En los testimonios de objeto directo oracional, el verbo subordinado es siempre un infinitivo ([3d]). La voz narrada contiene invariablemente verbos de habla ([3a] a [3d]) o derivados nominales de éstos ([3e]).

Esta categoría tiene, desde luego, funciones específicas y especializaciones de uso que, por cuestiones de espacio, no pueden abordarse aquí. Ya hemos dicho que, en términos narrativos, se produce una "reducción del discurso al acontecimiento". ${ }^{60}$ Desde un punto de vista pragmático, ello encierra la única finalidad esencial de referir el acto de habla ajeno, no la de representar las palabras de L2, como ocurre en todas las formas de los estilos directo e indirecto: "Si el discurso directo representa forma y contenido proposicional, y el discurso indirecto contenido proposicional, las formas narradas dan cuenta del acto verbal o del evento comunicativo en forma global". ${ }^{61}$ Esto explica el hecho de que todos los casos de voz narrada de mi corpus ostenten verbos de habla o bien derivados nominales de éstos, y que, como acabamos de ver, no siempre se represente el contenido del enunciado secundario.

Los casos de voz narrada integran el $27.8 \%$ (665/2396) de todo mi corpus. ${ }^{62}$ Las frecuencias relativas, para el total de titulares con discurso ajeno de cada periódico, son las siguientes: Reforma, 42.4\% (174/410); El Universal, 28.4\% (131/462);

${ }^{60}$ Genette (1972) 1989, 228.

${ }^{61}$ Fonte 1998, 34.

${ }^{62}$ Por diarios, la distribución global de la voz narrada es la siguiente: Reforma, 26.2\% (174/665); El Universal, 19.7\% (131/665); El Sol de México, 29.5\% (196/665); La Jornada, $13.8 \%$ (92/665); La Prensa, 10.8\% (72/665). 
Gráfica 3

Proporción de voz narrada en cada periódico

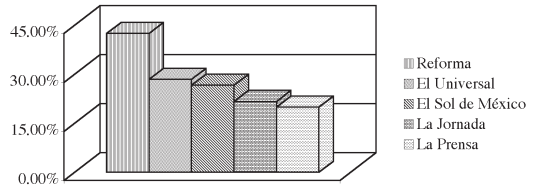

El Solde México, 26.6\%(196/737); La Jornada, 21.6\% (92/425); La Prensa, 19.9\% (72/362). Puede advertirse que más de dos quintas partes de los titulares de Reforma se codifican como voz narrada, mientras que, en los demás periódicos, la proporción oscila entre el 20 y el $30 \%$.

El $69.2 \%(460 / 665)$ de los testimonios de voz narrada corresponde a oraciones simples; el 29.5\% (196/665), a oraciones con infinitivo objetivo, y sólo el 1.4\% (9/665) a frases nominales.

\section{Formas mixtas}

Como sugiere su nombre, las formas mixtas constituyen fórmulas discursivas que combinan características de las otras tres modalidades del discurso ajeno, aquí llamadas puras: estilo directo, estilo indirecto y voz narrada. Ignoradas o segregadas en casi todos los estudios especializados en el discurso ajeno, ${ }^{63}$ las formas mixtas no han recibido especial atención sino hasta fechas relativamente recientes, en especial a partir

63 Jespersen (1924) 1968; RAE (1931) 1962, § 382, y 1973, \$3.19.4; Gili Gaya 1967 \$ $219 . I I$; Partee 1973; Wierzbicka 1974; Alcina y Blecua (1975) 2001, \$8.4.1; Li 1986; Maldonado 1991 y 1999, y Collins 2001, entre muchos otros. 
del fecundo trabajo de Cappelen y Lepore acerca de las variedades de la cita, donde por vez primera se señala la pobreza descriptiva de todo estudio de la representación discursiva que no las considere. ${ }^{64}$ Es preciso aclarar, sin embargo, que los estudios existentes se centran casi exclusivamente en algunos fenómenos de hibridación local.

A partir de las aportaciones de Hickmann relativas a la adquisición de ciertas estructuras básicas del discurso ajeno, ${ }^{65}$ concibo y clasifico las formas mixtas según comporten hibridaciones locales o globales. Hay hibridación local cuando una cláusula, ${ }^{66}$ integrada solamente por una frase, oración o período ${ }^{67}$ registra características de más de una variedad pura del discurso ajeno. Hay, en cambio, hibridación global cuando una cláusula está compuesta por dos frases, oraciones o períodos yuxtapuestos o coordinados que, tomados de manera aislada, comportan estructuras identificables con diferentes variedades puras del discurso ajeno. En los testimonios que recojo, estas formas tienen como origen, en cada caso, un mismo acto o macroacto de habla, y, por consiguiente, un mismo L2.

(4) a. Afirma Fox que tenía una "sólida" amistad con el gobernador fallecido [JOR 27/02/05: 30]

b. Seguirá Cuba comprando alimentos a EU "en condiciones aceptables" [SOL 26/02/05: 4/A, 2. ${ }^{\text {a] }}$

c. Piden aplicar "mano dura" contra criaderos clandestinos de cerdos [SOL 23/02/05: 7/B]

${ }^{64}$ Cappelen y Lepore 1997, 446.

${ }^{65}$ Hickmann 1993.

${ }^{66}$ En la tradición gramatical española, una cláusula es una "expresión con autonomía elocutiva - mejor que sintáctica - derivada de su plenitud conceptual" (Lope Blanch 1983,53); se trata, pues, de una unidad de comunicación y, por consiguiente, de pensamiento. Todos los encabezados de un periódico son cláusulas, por tanto.

${ }^{67}$ En conformidad con los planteamientos de Lope Blanch, entiendo por período una "expresión constituida por dos o más oraciones gramaticales entre las cuales se establece una sola relación sintáctica, ya coordinante, ya subordinante" (Lope Blanch 1983, 35). 
Ejemplifico, en la serie (4), las variedades de hibridación local que contienen mis materiales. En todas ellas, un constituyente marcado ortográficamente como retransmisión directa se incorpora a una estructura receptora que ostenta propiedades de alguna otra modalidad del discurso ajeno. En (4a) se observa una estructura receptora en estilo indirecto marcado, con verbo y conjunción expresos; en (4b), una en estilo indirecto no marcado, según se deduce al comparar el titular y el texto que encabeza, y en (4c), por último, una en voz narrada.

(5) a. Calderón podría ser el aspirante; "no creo que Santiago sea el hombre del Presidente", asegura Ramírez Acuก̃a [LAP 24/02/05: 8]

b. Urgen a Pemex 10,000 mdd; sus finanzas están en nivel crítico, dice Ramírez Corzo [LAP 22/02/05: 24].

c. Denuncian supuesto acecho contra una niña en Hidalgo de parte del padre; la querría secuestrar [SOL 21/02/05: 6/B]

d. Denuncian represión los transportistas de Edomex; marcharán hacia el Zócalo [soL 22/02/05: 5/A, 3. ${ }^{a}$ ]

e. Se pronuncia Enrique Martínez a favor de López O.; lo quieren excluir, afirma [LAP 23/02/05: 14]

La serie (5) contiene testimonios que ilustran las fórmulas de hibridación global presentes en mi corpus. En (5a), se yuxtaponen una estructura en estilo directo doblemente marcado y otra en estilo indirecto marcado por el uso de pospretérito con valor de potencial citativo. En (5b), una secuencia marcada como directa sucede a una reformulación analítica no marcada. Un segmento en voz narrada precede a otro en estilo indirecto marcado con pospretérito citativo en el encabezado (5c). Se yuxtaponen, en (5d), una oración en voz narrada y una secuencia en estilo indirecto no marcado. Por último, (5e) exhibe una hibridación global que asocia voz narrada y estilo directo marcado. 
Las formas mixtas integran la variedad del discurso ajeno menos abundante de mi corpus: representa apenas el $3.3 \%$ (78/2396) del total. ${ }^{68}$ Las frecuencias relativas, para el total de titulares con discurso ajeno de cada periódico, son las siguientes: La Jornada, 5.9\% (25/425); La Prensa, 4.7\% (17/362); Reforma, 2.7\% (11/410); El Universal, 2.4\% (11/462); El Sol de México, $1.9 \%$ (14/737). Es muy notorio que los diarios $L a$ Jornada y La Prensa registran frecuencias relativas de uso que casi duplican las de los demás periódicos.

Puede advertirse que, al menos en los titulares periodísticos, estas formas distan mucho de ser la variedad del discurso ajeno más abundante, como sugieren Cappelen y Lepore. ${ }^{69}$ En mis materiales, el $71.8 \%$ (56/78) de estas estructuras corresponde a casos de hibridación local, mientras que el $28.2 \%$ (22/78), a hibridación global.

Gráfica 4

Proporción de formas mixtas en cada periódico

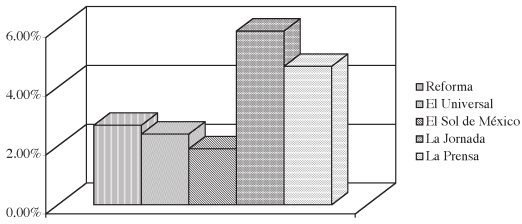

${ }_{68}^{6}$ Por diarios, la distribución global de la voz narrada es la siguiente: La Jornada, 32.1\% (25/78); La Prensa, 21.8\% (17/78); El Sol de México, 17.9\% (14/78); Reforma, 14.1\% (11/78); El Universal, $14.1 \%$ (11/78).

${ }^{69}$ Cappelen y Lepore $1997,429$. 


\section{Conclusiones}

Primera. He propuesto un modelo de análisis del discurso ajeno a partir de un corpus de titulares periodísticos. Si bien me he centrado en las singularidades que se presentan en este registro lingüístico, el esquema general puede hacerse extensivo a otros usos discursivos. El modelo se aleja de las clasificaciones tradicionales en la medida en que no se limita a fenómenos oracionales de reproducción discursiva: las formas narrativizadas y no marcadas del discurso ajeno evidencian la necesidad de una redefinición del objeto de estudio que considere su carácter heterogéneo, dinámico y complejo.

Segunda. El análisis cuantitativo permite conocer las dimensiones del sesgo que suponen las clasificaciones tradicionales. Al menos en lo concerniente a los encabezados periodísticos, puede hablarse de una omisión de hasta el 73.2\% (1753/2396) del universo de estudio en las clasificaciones más tradicionales, es decir, aquellas que se limitan exclusivamente a las formas marcadas de los estilos directo e indirecto.

Tercera. En el registro lingüístico de los titulares periodísticos, las formas no marcadas poseen una importancia insoslayable: representan el 42.2\% (1010/2396) del total de casos. De esta cifra, el 98.9\% (999/1010) corresponde al estilo indirecto no marcado; en realidad, este tipo de reformulación analítica integra el $41.7 \%$ (999/2396) de todo el corpus. Tradicionalmente olvidada en los estudios gramaticales, esta forma es la más abundante en los encabezados de prensa, y acaso también en otros muchos usos discursivos.

Cuarta. La frecuencia relativa de uso del estilo indirecto asciende al 46\% (1103/2396) de toda la muestra, cifra de la cual el $90.6 \%(999 / 1103)$ corresponde a formas no marcadas. Los testimonios de voz narrada suman el $27.8 \%(665 / 2396)$ del total de encabezados; los de estilo directo, el 23\% (550/2396), y los de formas mixtas, el $3.3 \%$ (78/2396). Puede deducirse 
Gráfica 5

Proporción de variedades generales del discurso ajeno

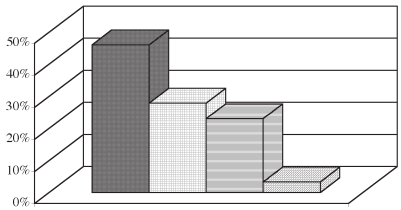

口Estilo indirecto

Voz narrada

口Estilo directo

口Formas mixtas

que los casos de formas no directas representan, por lo menos, el 73.8\% (1768/2396) del corpus.

Quinta. La proporción de formas no directas es mayoritaria en los cinco periódicos, aunque no de manera homogénea. Si no consideramos más que los casos de estilo indirecto y voz narrada, las frecuencias relativas son las siguientes: Reforma, 91\% (373/410); El Universal, 77.3\% (357/462); El Sol de México, 77.1\% (568/737); La Jornada, 61.2\% (260/425); La Prensa, 58\% (210/362). Si bien el porcentaje en este último diario es elevado, no es comparable con la incidencia que se observa en Reforma, mucho más dominante. En el cuadro 1 y en su correspondiente gráfica (la 6), pueden apreciarse más contrastes entre los periódicos de la muestra:

Cuadro 1

\begin{tabular}{|l|c|c|c|l|}
\cline { 2 - 5 } \multicolumn{1}{c|}{} & Estilo indirecto & Voz narrada & Estilo directo & Formas mixtas \\
\hline Reforma & $48.5 \%(199 / 410)$ & $42.4 \%(174 / 410)$ & $6.3 \%(26 / 410)$ & $2.7 \%(11 / 410)$ \\
\hline El Universal & $48.9 \%(226 / 462)$ & $28.4 \%(131 / 462)$ & $20.3 \%(94 / 462)$ & $2.4 \%(11 / 462)$ \\
\hline El Sol de México & $50.5 \%(372 / 737)$ & $26.6 \%(196 / 737)$ & $21.0 \%(155 / 737)$ & $1.9 \%(14 / 737)$ \\
\hline La Jornada & $39.5 \%(168 / 425)$ & $21.6 \%(92 / 425)$ & $32.9 \%(140 / 425)$ & $5.9 \%(25 / 425)$ \\
\hline La Prensa & $38.1 \%(138 / 362)$ & $19.9 \%(72 / 362)$ & $37.3 \%(135 / 362)$ & $4.7 \%(17 / 362)$ \\
\hline
\end{tabular}


Gráfica 6

Proporciones generales del discurso ajeno por diario

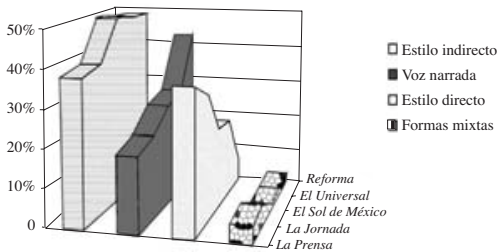

Sexta. Dentro de esta tendencia general, que apunta hacia el uso mayoritario del estilo indirecto y minoritario de las formas mixtas, se identifican tres comportamientos diferentes en la codificación lingüística de los titulares periodísticos:

Comportamiento 1: Mayor frecuencia de uso de estilo directo que de voz narrada.

Comportamiento 2: Equilibrio en frecuencias de uso entre estilo directo y voz narrada.

Comportamiento 3: Mayor frecuencia de uso de voz narrada que de estilo directo.

El comportamiento 1 es adoptado por los diarios La Prensa y La Jornada: mientras que la voz narrada se emplea en un $20 \%$ de los encabezados, el estilo directo oscila entre el 30 y el $40 \%$. Si consideramos que casi todas formas mixtas son casos de hibridación local, no es extraño que sean estos diarios los que con mayor frecuencia publiquen mezclas de variedades puras. También son éstos los periódicos que ofrecen menos testimonios de estilo indirecto. La tendencia general está, pues, menos acentuada en estas publicaciones que en las demás. 
Reforma exhibe el comportamiento 3, es decir, el inverso: más del $40 \%$ de sus titulares está en voz narrada, y menos del $10 \%$ en estilo directo. En este diario se observa claramente una polarización que remarca la tendencia general del discurso de los titulares: hay casi tantos encabezados en voz narrada como en estilo indirecto, y casi tan pocos en estilo directo como en modalidades híbridas.

Se observa el comportamiento 2 en los periódicos El Universal y El Sol de México: en ellos, el estilo directo y la voz narrada representan entre el $20 \%$ y el $30 \%$ de todos los casos. A pesar de que las frecuencias de la segunda son un poco más altas que las del primero, situación que sugiere mayor proximidad con el comportamiento 3 que con el 1, este equilibrio relativo supone una actitud más o menos neutra con respecto a la preferencia entre las formas narrativizadas y las que conllevan retransmisiones presuntamente literales. Desde luego, no ocurre lo mismo con la tendencia general, pues son estos diarios los que mayor contraste exhiben entre estilo indirecto y formas mixtas.

Séptima. Las modalidades discursivas aquí estudiadas se diferencian gradualmente según sus propiedades mimético-diegéticas: la más mimética es, desde luego, el estilo directo, y la más diegética, la voz narrada. El estilo indirecto ocupa una posición intermedia. Las distintas subvariedades, así como las formas mixtas, representan estadios diversos de este continuo. De manera general, es posible representarlo de la siguiente manera:

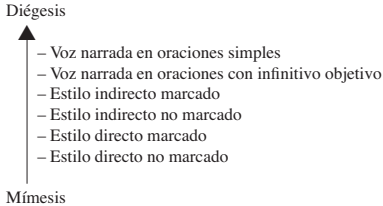


Los tres comportamientos generales que he identificado encuentran su motivación en esta escala. El comportamiento 1 supone una preferencia hacia las formas miméticas del discurso ajeno; el comportamiento 3 , en cambio, hacia las formas diegéticas; por último, el comportamiento 2 tiende a un equilibrio entre mímesis y diégesis. Se comprueba, pues, que las organizaciones informativas tienen claras preferencias - directrices editoriales - con respecto a los procedimientos lingüísticos de alusión o representación de las palabras ajenas en sus encabezados, y que estas inclinaciones, acentuadas por la repetición habitual, se basan en las capacidades mimético-diegéticas de las modalidades discursivas. Parece que la expresividad que acarrea el comportamiento mimético es buscada mediante el comportamiento 1 , y rechazada mediante el comportamiento 3 .

\section{Bibliografía}

Alarcos Llorach, Emilio. 1977. "Lenguaje de los titulares", en Lenguaje en periodismo escrito, F. Lázaro Carreter (ed.). Madrid: Fundación Juan March (Serie Universitaria, 37): 125-148. Alcina Franch, Juan, y José Manuel Blecua. (1975) 2001. Gramática española. 11. a ed., Barcelona: Ariel (Letras e Ideas).

BAJTín, Mijaíl Mijáilovich. (1935) 1986. "La palabra en la novela", en Problemas literarios y estéticos. Trad. Alfredo Caballero. La Habana: Arte y Literatura: 83-268.

-. (1963) 1986. Problemas de la poética de Dostoievski. Trad. Tatiana Bubnova. México: FCE (Breviarios, 417).

BAL, Mieke. (1978) 1990. Teoría de la narrativa (Una introducción a la narratología). Trad. Javier Franco, 3. ${ }^{a}$ ed., Madrid: Cátedra (Crítica y Estudios Literarios).

BALLY, Charles. 1912. "Le style indirect libre en français moderne", Germanisch-Romanische Monatsschrift, 4: 549-556, 597-606.

BANFIELD, Ann. 1973. "Narrative Style and the Grammar of Direct and Indirect Speech", Foundations of Language, 10 (1): 1-39. 
Beltrán Almería, Luis. 1992. Palabras transparentes. La configuración del discurso del personaje en la novela. Madrid: Cátedra (Crítica y Estudios Literarios).

Bell, Allan. 1991. The Language of the News Media. Oxford: Blackwell.

CAPPElen, Herman, y Ernie LePORE. 1997. "Varieties of Quotation", Mind, 423: 429-450.

-. 2005. "Varieties of Quotation Revisited", Belgian Journal of Linguistics, 17: 51-75.

Casado Velarde, Manuel. 1984. "Semiótica de los titulares: pautas para el análisis de los titulares periodísticos", en Teoría semiótica. Actas del Congreso Internacional sobre Semiótica e Hispanismo, vol. 1, M. Á. Garrido Gallardo (ed.). Madrid: CSIC: 235242.

Collins, Daniel E. 2001. Reanimated Voices: Speech Reporting in a Historical-Pragmatic Perspective. Amsterdam-Philadelphia: John Benjamins (Pragmatics \& Beyond, New Series, 85).

ComrIE, Bernard. 1986. "Tense in Indirect Speech", Folia Linguistica, 20 (3): 265-296.

Coulmas, Florian (ed.), 1986. Direct and Indirect Speech, Berlin: Mouton de Gruyter (Trends in Linguistics: Studies and Monographs, 31).

-. 1986b. "Reported Speech: Some General Issues", en Coulmas (ed.): $1-28$.

Chafe, Wallace. 1994. Discourse, Consciousness, and Time: The Flow and Displacement of Conscious Experience in Speaking and Writing. Chicago: University of Chicago Press.

Ducrot, Oswald. (1984) 1986. El decir y lo dicho. Trad. Irene Agoff. Barcelona: Paidós (Paidós Comunicación, 24).

Eco, Umberto. 1977. "Guida all'ipretazione del linguagio giornalistico", en La lingua italiana oggi: un problema scolastico e socia$l e$, L. Renzi y M. A. Cortelazzo (eds.). Bologna: Società editrice il Mulino (Problemi e prospective. Serie di linguistica e critica litteraria): 165-187.

Emig, Elmer. 1927. "The Connotation of Newspaper Headlines", Journalism Quarterly, 4 (4): 53-59.

FAIRClough, Norman. 1988. "Discourse Representation in Media Discourse", Sociolinguistics, 17 (2): 125-139. 
Fillmore, Charles. 1982. "Frame Semantics", Linguistics in the Morning Calm. Selected Papers from SICOL-1981, The Linguistic Society of Korea (ed.). Seoul: Hanshing Publishing Company.

FonTE, Irene. 1996. "Las formas narrativizadas del discurso reportado en la prensa", en Español y lenguas indoamericanas: estudios y aplicaciones, H. Muñoz Cruz (ed.). México: Uam-Iztapalapa (Investigaciones Lingüísticas, 3): 41-57.

-. 1998. Cuba 1906-1921: versiones de la nación en el discurso periodístico. México: El Colegio de México (tesis).

-. 2002. La nación cubana y Estados Unidos: un estudio del discurso periodístico (1906-1921). México: El Colegio de México-UAM-Iztapalapa (Estudios de Lingüística y Literatura, 45).

GenetTe, Gérard. (1972) 1989. Figuras III. Trad. Carlos Manzano. Barcelona: Lumen (Palabra Crítica).

-. (1993) 1998. Nuevo discurso del relato. Trad. Marisa Rodríguez Tapia. Madrid: Cátedra (Crítica y Estudios Literarios).

GILI GAYA, Samuel. 1967. Curso superior de sintaxis española. 9. ${ }^{a}$ ed., Barcelona: Bibliograf.

GIVÓN, Talmy. 1995. Functionalism and Grammar. AmsterdamPhiladelphia: John Benjamins.

GoldBerg, Adele E. 1995. Constructions: A Construction Grammar Approach to Argument Structure. Chicago: University of Chicago Press.

Haberland, Hartmut. 1986. "Reported Speech in Danish", en Coulmas (ed.): 219-253.

Hand, Michael. 1991. "On Saying That Again", Linguistics and Philosophy, 14: 349-365.

Hickmann, Maya. 1993. "The Boundaries of Reported Speech in Narrative Discourse: Some Developmental Aspects", en Reflexive Language: Reported Speech and Metapragmatics, J. A. Lucy (ed.). Cambridge: Cambridge University Press.

JAKOBSON, Roman. (1936-1963) 1981. Ensayos de lingüística general. Trad. Josep M. Pujol y Jem Cabanes, 2. ${ }^{\text {a }}$ ed., Barcelona: Seix Barral (Biblioteca Breve).

JANSSEN, Theo A. J. M. y Wim VAn DER WurfF. 1996. "Introductory Remarks on Reported Speech and Thought", en Reported Speech, T. A. J. M. Janssen y W. VAN DER WURFF (eds.). Amsterdam-Philadelphia: John Benjamins: 1-12. 
KAY, Paul. 1997. "Construction Grammar", en Words and the Grammar of Context. Stanford: Center for the Study of Language and Information: 123-131.

LAPESA, Rafael. 1977. "Tendencias y problemas actuales de la lengua española”, en Comunicación y lenguaje, R. Lapesa (ed.). Madrid: Karpos: 207-229.

LeECH, Geoffrey N., y Michael H. ShorT. 1981. Style in Fiction. A Linguistic Introduction to English Fictional Prose. New York: Longman (English Language, 13).

LI, Charles N. 1986. "Direct and indirect speech: A functional study", en Coulmas (ed.): 29-45.

LoPe Blanch, Juan M. 1983. Análisis gramatical del discurso. México: UnAm (Publicaciones del Centro de Lingüística Hispánica, 17).

Maingueneau, Dominique. 1981. Approche de l'énonciation en linguistique française. Paris: Hachette (Langue, Linguistique, Communication).

Maldonado, Concepción. 1991. Discurso directo y discurso indirecto. Madrid: Taurus Universitaria (Gramática del Español, 3).

-, 1999. "Discurso directo y discurso indirecto", en Gramática descriptiva de la lengua española, vol. 3: Entre la oración y el discurso, y Morfología I. Bosque y V. Demonte (eds.). Madrid: Espasa Calpe-Real Academia Española-Fundación José Ortega y Gasset (Nebrija y Bello): 3549-3595.

MCHALE, Brian. 1978. "Free Indirect Discourse: A Survey of Recent Accounts", Poetics and the Theory of Literature, 3: 249-287.

Nadal Palazón, Juan. 2009. El discurso ajeno en los titulares de la prensa mexicana. México: UNAM (tesis) (Posgrado, 37).

NølKe, Henning, Kjersti FløtTum y Coco Norén. 2004. ScaPoLine. La théorie Scandinave de la polyphonie linguistique. Paris: Kimé.

PAGE, Norman. 1973. Speech in the English Novel. London: Macmillan Press.

PARmentier, Richard J. 1993. "The Political Function of Reported Speech: A Belauan Example”, en Reflexive Language. Reported Speech and Metapragmatics, J. A. Lucy (ed.). Cambridge: Cambridge University Press.

Partee, Barbara Hall. 1973. "The Syntax and Semantics of Quotation", en A Festschrift for Morris Halle, S. R. Anderson y 
P. Kiparsky (eds). San Francisco: Holt, Reinhart and Winston: 410-418.

Perret, Michèle. 1994. L'Énonciation en grammaire du texte. Paris: Éditions Nathan.

Real ACAdemia Española. (1931) 1962. Gramática de la lengua española. Madrid: Espasa Calpe.

-. 1973. Esbozo de una nueva gramática de la lengua española. Madrid: Espasa Calpe.

REYES, Graciela. 1984. Polifonía textual: la citación en el relato literario. Madrid: Gredos (Biblioteca Románica Hispánica, II: Estudios y Ensayos, 340).

- 1993. Los procedimientos de cita: estilo directo y estilo indirecto. Madrid: Arco Libros (Cuadernos de Lengua Española, J).

-. 1994. "La cita en español: gramática y pragmática", Gramática del español, V. Demonte (ed.). México: El Colegio de México (Publicaciones de la Nueva Revista de Filología Hispánica, 6): 591-627.

Romero Álvarez, María de Lourdes. 2006. La realidad construida en el periodismo. Reflexiones teóricas. México: unAm-Miguel Ángel Porrúa.

SAKITA, Tomoko I. 2002. Reporting Discourse, Tense, and Cognition. Oxford: Elsevier.

SÁnchez-Rey, Alfonso. 1991. El lenguaje literario de la "nueva novela" hispánica. Madrid: Editorial MAPFRE.

STEEL, Brian. 1971. "Los estilos funcionales y la enseñanza del idioma", Español Actual, 18: 9-18.

ToOLAN, Michael J. 1988. Narrative: A Critical Linguistic Introduction. London: Routledge.

VAN DiJK, Teun Adrianus. (1988) 1997. “¿Cómo se lleva una minoría a los titulares? Minorías étnicas en la prensa”, en Racismo y análisis crítico de los medios. Trad. Montserrat Basté Kraan. Barcelona: Paidós (Paidós Comunicación, 82).

Voloshinov, Valentin Nikólaievich. (1929) 1992. El marxismo y la filosofia del lenguaje. Trad. Tatiana Bubnova. Madrid: Alianza (Alianza Universidad, 740).

WaLES, Katie. 1989. A Dictionary of Stylistics. London: Longman.

WAUGH, Linda R. 1995. "Reported Speech in Journalistic Discourse: The Relation of Function and Text". Text, 15 (1): 129-173. 
WierzBICKA, Anna. 1974. "The Semantics of Direct and Indirect

Discourse", Papers in Linguistics, 7 (3-4): 267-307.
Abreviaturas
$\mathrm{JOR}=$ La Jornada
LAP $=$ La Prensa
REF $=$ Reforma
$\mathrm{SOL}=$ El Sol de México
$\mathrm{UNI}=$ El Universal 